\title{
Acoustic Investigations on Pure and Rare Earth Ion Doped $\mathrm{MgO}-\mathrm{ZnO}-\mathrm{B} 2 \mathrm{O} 3$ Glasses
}

\author{
M. Zahir Ahmed ${ }^{1}$, S. Haranatha Sarma ${ }^{2}$ \\ ${ }^{1,2}$ Department of Physics Osmania College, Kurnool, Andhra Pradesh, India.Pincode-518001
}

\begin{abstract}
Rare earth ion doped $\mathrm{MgO}-\mathrm{ZnO}-\mathrm{B}_{2} \mathrm{O}_{3}$ glasses were prepared by rapid melt quench method. Accurately measured the density of the samples. Ultrasonic velocity measurements were carried on the prepared samples by piezoelectric composite resonance method and investigated acoustic properties. Various acoustic, elastic and mechanical constants were derived from these investigations. All these parameters are found to increase with increasing atomic number $Z$ of the rare earth ions and found to decrease with increasing temperature of measurement. The results of these parameters have been discussed in terms of the structural and physical properties of the prepared glasses.
\end{abstract}

Keywords: acoustic impedance, borate glass, debye temp., elastic moduli, micro hardness, Poisson's ratio, rare earth ions

\section{Introduction}

The acoustical properties are particularly suitable for describing microstructure and the dynamics of the glasses. The elastic properties are related to microscopic properties through the behaviour of the network and the modifier giving valuable information about several physical properties like elastic moduli (longitudinal, Young's, bulk and shear), Poisson's ratio, acoustic impedance, micro hardness, Debye temperature and thermal expansion coefficient [1]-[3]

M Rami Reddy et.al [4] reported Acoustic investigations on $\mathrm{PbO}-\mathrm{Al}_{2} \mathrm{O}_{3}-\mathrm{B}_{2} \mathrm{O}_{3}$ glasses doped with $\mathrm{Pr}^{3+}, \mathrm{Nd}^{3+}, \mathrm{Sm}^{3+}, \mathrm{Eu}^{3+}$, $\mathrm{Tb}^{3+}, \mathrm{Dy}^{3+}, \mathrm{Ho}^{3+}, \mathrm{Er}^{3+}$ and $\mathrm{Yb}^{3+}$. Elastic moduli $(\mathrm{E}, \mathrm{G})$, Poisson's ratio (s), microhardness $(\mathrm{H})$ and some thermodynamical parameters such as Debye temperature $(\theta \mathrm{D})$, diffusion constant (Di), latent heat of melting ( $\square \mathrm{Hm}$ ) parameters were evaluated and found to increase with increasing atomic number $\mathrm{Z}$ of the rare-earth ions and found to decrease with increasing temperature of measurement. P. Vasantharani et.al [4] studied physical and elastic properties of the ternary glass system of $(50-\mathrm{x}) \mathrm{Li}_{2} \mathrm{O}-50 \mathrm{~B}_{2} \mathrm{O}_{3}-\mathrm{xNa}_{2} \mathrm{O}$ (where $\mathrm{x}=10,15,20,25$ and $30 \mathrm{~mol} \%$ ) with different compositions. AN. Kannappan et.al [5] evaluated various elastic and mechanical parameters of $\mathrm{Na}_{2} \mathrm{CO}_{3}-\mathrm{ZnO}-\mathrm{B}_{2} \mathrm{O}_{3}$ (SZB) and $\mathrm{Na}_{2} \mathrm{CO}_{3}-\mathrm{PbO}-\mathrm{B}_{2} \mathrm{O}_{3}$ (SLB) composition glasses from ultrasonic measurements. Their findings reveal that acoustical, elastic and mechanical parameters of the glass specimen (SZB, SLB) throw light on the rigidity and compactness in structural network and the SZB glass possess higher rigidity, strength and compactness in structural network over the SLB glass.

Borate glasses are one of the most popular and excellent glass forming materials. Upon addition of alkali oxides to $\mathrm{B}_{2} \mathrm{O}_{3}$, the covalent network of amorphous boron oxide causes considerable changes, resulting in the creation of anionic sites that accommodate the modifying alkali cations [4]. With the presence of property modifying salts like $\mathrm{ZnO}$ with $\mathrm{B}_{2} \mathrm{O}_{3}$ glass network could significantly improve different properties like very glass nature, mechanical strength and thermal stability with an extended chemical durability. Such glasses could be found as more supportive materials for their applications in optical communications (optical fibers), laser hosts, optical filters, $\gamma$-ray absorbers, photonic devices etc [7] - [16]. M. Venkateswarlu et.al reported structural, thermal and optical properties of $\mathrm{Sm} 3+, \mathrm{Dy}^{3}+, \mathrm{Eu}^{3+}$ and $\mathrm{Tb}^{3+}$ ions doped Borate Zinc Magnesium Glasses (MZB glasses). Their findings reveal that MZB glasses are amorphous, transparent, moisture resistant and stable and brightly luminescent. Under UV light MZB glasses doped with $\mathrm{Sm}^{3+}, \mathrm{Dy}^{3+}, \mathrm{Eu}^{3+}$ and $\mathrm{Tb}^{3+}$ shown bright orange, blue, red and green emissions respectively. They also reported the transformation of $\mathrm{BO}_{3}$ triangles into $\mathrm{BO}_{4}$ tetrahedral from the FTIR measurements. [17], [18]. This makes MZB glasses as promising optical luminescent materials with technological importance.

Based on these findings to throw some light on the mechanical strength and elastic nature of the MZB glasses, acoustic investigations were carried out with and without rare-earth dopants in the present work. To the best of our knowledge acoustic investigations on MZB glasses were not reported.

\section{Aims and Objectives}

Synthesis of pure and rare earth ion doped MZB glasses and to investigate their mechanical strength.

\section{Materials and Methods}

\subsection{Preparation of Samples}

The borate zinc magnesium (MZB) glasses in the following chemical composition containing $\mathrm{Sm}^{3+}, \mathrm{Dy}^{3+}, \mathrm{Eu}^{3+}$, or $\mathrm{Tb}^{3+}$ ions in $0.2 \mathrm{~mol} \%$ each separately, along with a host glass as well were prepared by rapid melt quenching method.

\footnotetext{
i. Host glass: $65 \mathrm{~B}_{2} \mathrm{O}_{3}-20 \mathrm{ZnO}-15 \mathrm{MgO}(\mathrm{MZB})$

ii. $\left(\mathrm{Sm}^{3+}\right)$ 0.2: $64.8 \mathrm{~B}_{2} \mathrm{O}_{3}-20 \mathrm{ZnO}-15 \mathrm{MgO}$,

iii. $\left(\mathrm{Dy}^{3+}\right)$ 0.2: $64.8 \mathrm{~B}_{2} \mathrm{O}_{3}-20 \mathrm{ZnO}-15 \mathrm{MgO}$,

iv. $\left(\mathrm{Eu}^{3+}\right) 0.2: 64.8 \mathrm{~B}_{2} \mathrm{O}_{3}-20 \mathrm{ZnO}-15 \mathrm{MgO}, \&$

v. $\left(\mathrm{Tb}^{3+}\right) 0.2: 64.8 \mathrm{~B}_{2} \mathrm{O}_{3}-20 \mathrm{ZnO}-15 \mathrm{MgO}$,
} 


\section{International Journal of Science and Research (IJSR) \\ ISSN (Online): 2319-7064}

Index Copernicus Value (2015): 78.96 | Impact Factor (2015): 6.391

The starting materials used in the present work were reagent grade of $\mathrm{H}_{3} \mathrm{BO}_{3}, \mathrm{ZnCO}_{3}, \mathrm{MgCO}_{3}, \mathrm{Sm}_{2} \mathrm{O}_{3}, \mathrm{Dy}_{2} \mathrm{O}_{3}, \mathrm{Eu}_{2} \mathrm{O}_{3}$ and $\mathrm{Tb}_{4} \mathrm{O}_{7}$. All weighted chemicals were powdered finely and mixed thoroughly before each batch $(10 \mathrm{~g})$ was melt in porceline crucibles in an electrical furnace for an hour, at $980^{\circ} \mathrm{C}$. These melts were quenched in between two brass plates to obtain $2-3 \mathrm{~cm}$ diameter optical glass discs of $0.3 \mathrm{~cm}$ thickness. The glasses were then ground and finely polished. These glasses thus obtained were used for further characterizations.

\subsection{Measurement of Density}

The density (d) of the glasses was determined to an accuracy of 0.001 by the Archimedes' Principle using xylene (99.99\% pure) as the buoyant liquid. The weight of the glass samples was measured in a single pan balance with an accuracy of $0.0001 \mathrm{~g}$. The density was calculated using the formula

$$
d=d_{x} \frac{W_{1}}{W_{1}-W_{2}}
$$

where $W_{1}$ and $W_{2}$ are the weights of the glass samples in air and in xylene and $\mathrm{dx}$ is the density of the xylene at $303 \mathrm{~K}$.

\subsection{Measurement of Ultrasonic Velocity}

The ultrasonic velocities in the samples were measured with a piezoelectric composite oscillator apparatus (Mittal Enterprises, New Delhi) by resonance method. The final dimensions of the glasses used ere $(2 \times 0.25 \times 0.25 \mathrm{~cm})$ and ( $2 \mathrm{~cm}$ long and $0 \cdot 25 \mathrm{~cm}$ in diameter) for longitudinal and shear velocity measurements respectively. These dimensions were almost identical to those of X-cut $0 \cdot 13 \mathrm{MHz}$ quartz transducers used in the measurements. Since the ultrasonic measurements on the present samples were made at $303 \mathrm{~K}$ and $373 \mathrm{~K}$ which are far below when compared with the melting temperature of the glasses $\left(\approx 980^{\circ} \mathrm{C}\right)$, density of the samples in the entire present experimental range of temperature, was taken as constant. If fq and fc are the resonance frequencies of the transducer and the composite bar, respectively, the resonant frequency (fs) of the glass samples was determined using the relation

$$
f_{s}=f_{c}+\frac{m}{m_{s}}\left(f_{c}-f_{q}\right)
$$

where $\mathrm{m}_{\mathrm{q}}$ and $\mathrm{m}_{\mathrm{s}}$ are the masses of the transducer and glass sample respectively.

Using the value of length (1) and density (d) of the specimen, the velocity of ultrasonic waves in the specimen (U) and compressibility $(\beta)$ can be calculated using the following relations

$$
\begin{aligned}
& U=2 * f_{s} * l \\
& \beta=\frac{1}{d^{*} v^{2}}
\end{aligned}
$$

\subsection{Theory and Calculations}

Longitudinal Modulus
Shear Modulus
Shear Modulus

$$
\begin{aligned}
& L=d U_{l}^{2} \\
& G=d U_{s}^{2}
\end{aligned}
$$

Bulk Modulus

Young's Modulus

Poisson's Ratio

Acoustic mpedance

Micro Hardness

The mean sound

velocity

Thermal Expansion

Coefficient

Diffusion Constant

Debye Temperature

coefficient of internal friction $Q^{-1}=\frac{\Delta f}{\sqrt{3} f_{r}}$

$$
K=L-4 / 3 G
$$$$
\mathrm{Y}=(1+\sigma) 2 G
$$$$
\sigma=(L-2 G) / 2(L-G)
$$$$
z=U_{l} d
$$$$
\mathrm{H}=(1-2 \sigma) Y / 6(1+\sigma)
$$$$
U_{m}=\left[1 / 3\left(2 / U^{3}+1 / U^{3}\right)\right]^{-\frac{\vdots}{2}}
$$$$
\alpha_{v}=23.2\left(U_{l}-0.57457\right)
$$$$
D_{i}=k_{B} r_{i}^{2} \theta_{D} / 96 h
$$$$
\theta_{D}=h / k_{B}\left(9 N / 4 \pi V_{m}\right) U_{m}
$$

\section{Results and Discussion}

From the measured values of density (d) and calculated average molecular weight $\mathrm{M}$, various physical parameters such as $\mathrm{Ln}^{3+}$ ion concentration (Ni), mean $\mathrm{Ln}^{3+}$ ion separation distance (Ri), and field strength (Fi), which are useful for understanding the elastic properties of these glasses are evaluated and presented in table 1

Table 1: Various physical properties of MZB: $\mathrm{Ln}^{3+}$ glasses

\begin{tabular}{|c|c|c|c|c|c|c|}
\hline Glass & $\begin{array}{c}d \\
\left(\mathrm{~g} / \mathrm{cm}^{3}\right)\end{array}$ & $M$ & $\begin{array}{c}\mathrm{Ni}\left(10^{22}\right) \\
\left(\text { ions } / \mathrm{cm}^{3}\right)\end{array}$ & $R_{i}(A)$ & $\begin{array}{c}F_{i-10^{16}} \\
\left(\mathrm{~cm}^{-2}\right)\end{array}$ & $\begin{array}{c}N\left[E_{F}\right]-10^{20} \\
\left(\mathrm{eV}^{I} \mathrm{~cm}^{3}\right)\end{array}$ \\
\hline $\mathrm{Sm}^{3+}$ & 3.005 & 101.9 & 1.95 & 4.01 & 0.124 & 4.84 \\
\hline $\mathrm{Eu}^{3+}$ & 2.99 & 102.8 & 1.87 & 4.09 & 0.123 & 4.61 \\
\hline $\mathrm{Tb}^{3+}$ & 2.844 & 103.1 & 1.76 & 4.12 & 0.131 & 4.25 \\
\hline $\mathrm{Dy}^{3+}$ & 2.715 & 103.8 & 1.69 & 4.19 & 0.129 & 3.83 \\
\hline
\end{tabular}

Figure 1A shows longitudinal resonance curves obtained at room temperature for MZB glasses doped with $\mathrm{Sm}^{3+}, \mathrm{Eu}^{3+}$ and $\mathrm{Tb}^{3+}$; it is observed that these resonance curves exhibit the sharpening of the peaks with a shift in the resonance frequency towards higher frequencies with ascending peak heights as the atomic number $\mathrm{Z}$ of the rare- earth ion is increased.

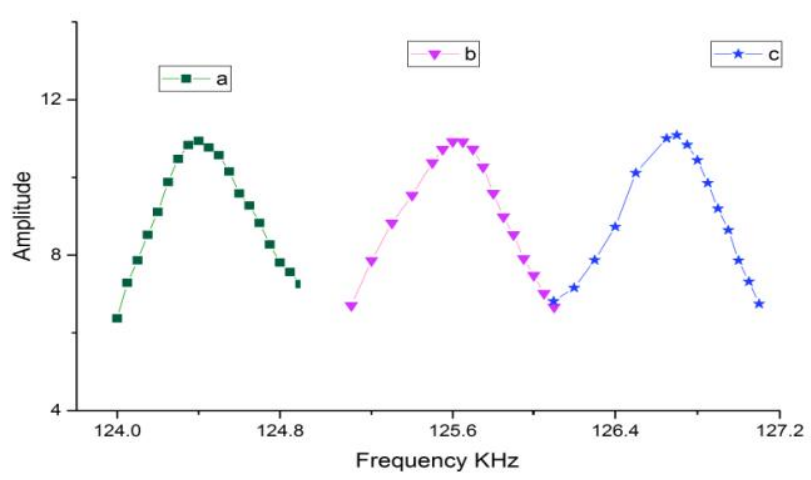

Figure 1A: Longitudinal resonance curves of MZB glass with different rare earth ions (a) $\mathrm{Sm}^{3+}$, (b) $\mathrm{Eu}^{3+}$ and (c) $\mathrm{Tb}^{3+}$

Fig. 1B shows the longitudinal resonance curves of $\mathrm{Tb}^{3+}$ doped MZB glasses drawn at different temperatures; we observe the broadening of the resonance curves with resonance frequency being shifted towards the lower frequencies with increasing half widths and descending peak heights, with increase in the temperatures of measurements. Similar observations were made by [4]. 


\section{International Journal of Science and Research (IJSR) \\ ISSN (Online): 2319-7064}

Index Copernicus Value (2015): 78.96 Impact Factor (2015): 6.391

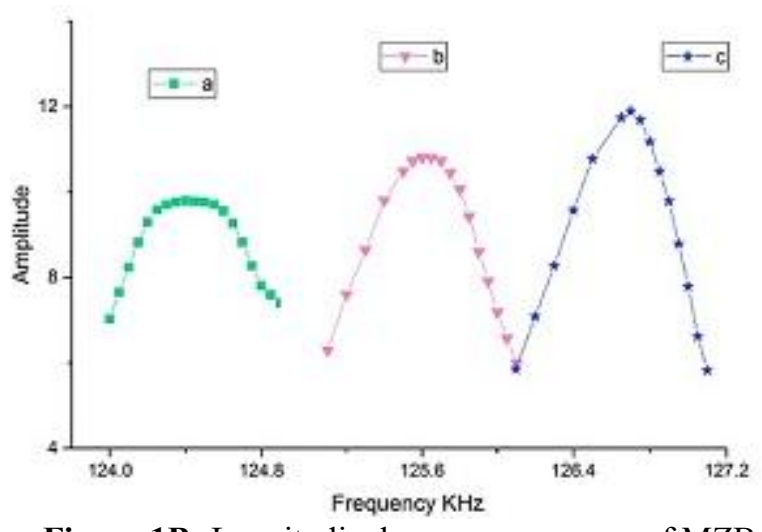

Figure 1B: Longitudinal resonance curves of MZB glass doped with $\mathrm{Tb}^{3+}$ at (a) $30^{\circ} \mathrm{C}$, (b) $100^{\circ} \mathrm{C}$ and (c) $160^{\circ} \mathrm{C}$.

Fig. 2 depicts the variation of coefficient of internal friction $\left(\mathrm{Q}^{-1}\right)$ with atomic number $(\mathrm{Z})$ of the rare-earth dopants of MZB glasses at $30^{\circ} \mathrm{C}$ and $100^{\circ} \mathrm{C}$. It is observed that there is a decrease in the coefficient of internal friction at fixed

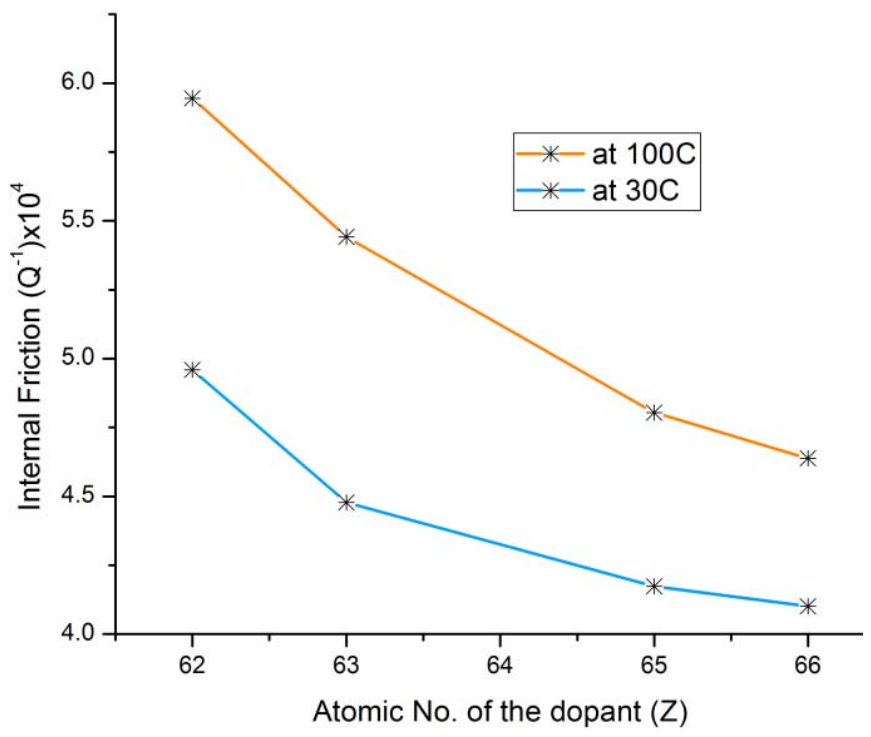

Figure 2: Variation of internal friction with atomic no. of rare-earth ion of MZB glass

temperature with a decrease in the ionic radius (or with increase in the atomic number) of the rare-earth dopant (from $\mathrm{Sm}^{3+}$ to $\left.\mathrm{Dy}^{3+}\right)$. This is apparently due to the successive decrease in the depolymerisation. This is further confirmed by a slight increase in the microhardness $(\mathrm{H})$ of the MZB: $\mathrm{Ln}^{3+}$ glasses with increase in the atomic number $(\mathrm{Z})$ of $\mathrm{Ln}^{3+}$ ions as given in table 2 [4].

Table 2: Elastic Properties of MZB: $\mathrm{Ln}^{3+}$ glasses

\begin{tabular}{|c|c|c|c|c|c|c|}
\hline \multirow{2}{*}{ Glass } & \multicolumn{2}{|c|}{$Y(G P a)$} & \multicolumn{2}{|c|}{$G(G P a)$} & $\sigma$ & \multirow{2}{*}{$\begin{array}{c}H \\
(G P a)\end{array}$} \\
\hline & $30^{\circ} \mathrm{C}$ & $100^{\circ} \mathrm{C}$ & $30^{\circ} \mathrm{C}$ & $100^{\circ} \mathrm{C}$ & $30^{\circ} \mathrm{C}$ & \\
\hline Pure & 57.24 & & 22.86 & & 0.311 & 2.84 \\
\hline $\mathrm{Sm}^{3+}$ & 48.71 & 46.65 & 18.61 & 16.85 & 0.304 & 2.37 \\
\hline $\mathrm{Eu}^{3+}$ & 51.39 & 49.1 & 19.64 & 17.98 & 0.308 & 2.51 \\
\hline $\mathrm{Tb}^{3+}$ & 54.44 & 52.52 & 20.80 & 18.24 & 0.312 & 2.66 \\
\hline $\mathrm{Dy}^{3+}$ & 55.65 & 53.14 & 21.27 & 20.04 & 0.318 & 2.71 \\
\hline
\end{tabular}

The values of Young's modulus (Y) and shear modulus (G), at room temperature for pure MZB glass are found to be 57.24 and $22.86 \mathrm{GPa}$ respectively. when these glasses are doped with $\mathrm{Sm}^{3+}$ ions, the values of $\mathrm{Y}$ and $\mathrm{G}$ decreased to
48.71 and 18.61 respectively. However, the successive increase in the atomic number $(Z)$ of the dopant caused a gradual increase in these values. Fig. 3 shows the variation of Young's modulus (Y) and shear modulus (G) with atomic number $(Z)$ of the rare-earth dopants of MZB: $\operatorname{Ln}^{3+}$ glasses at $30^{\circ} \mathrm{C}$.

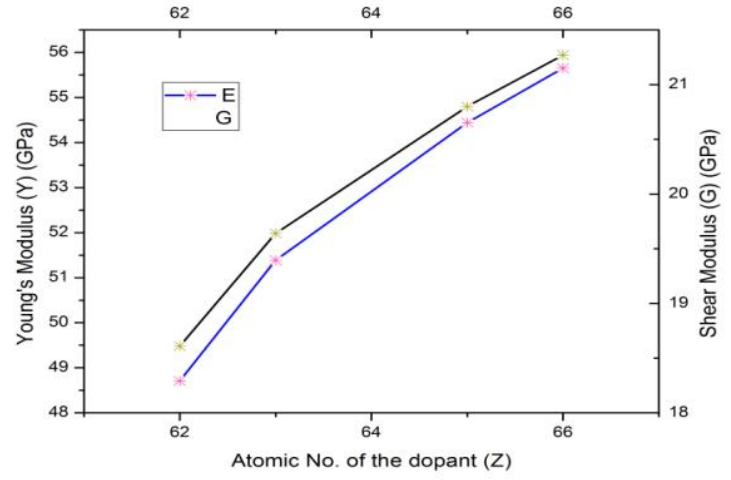

Figure 3: Variation of Young's modulus (Y) and Shear modulus $(\mathrm{G})$ of MZB glass with atomic no. of rare-earth ion

Fig. 4, Fig. 5 and Fig. 6 and Fig. 7 depict the isotherms of Debye temperature $\left(\theta_{\mathrm{D}}\right)$, latent heat of melting $(\Delta \mathrm{Hm})$, mean velocity $(\mathrm{Um})$ and diffusion constant $\left(\mathrm{D}_{\mathrm{i}}\right)$ respectively. All of them show increasing behaviour with the increase of atomic number $(Z)$ except debye temperature. This may be due to the decrease of atomic size (known as lanthanide contraction) which in turn causes a decrease in the degree of depolymerisation of glass network; this is also borne out by decrease in the values of density of localized defect states $(\mathrm{N}[\mathrm{EF}])$ with increase in atomic number $(\mathrm{Z})$ as given in Table 1.

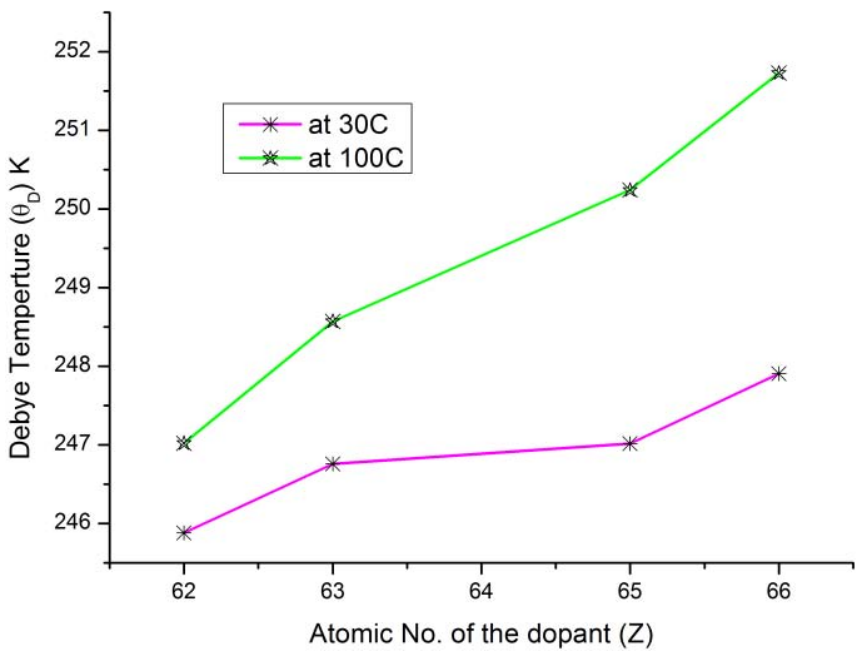

Figure 4: Variation of Debye Temperature $\left(\theta_{D}\right)$ of MZB glass with atomic no. of rare-earth ion 


\section{International Journal of Science and Research (IJSR)}

ISSN (Online): 2319-7064

Index Copernicus Value (2015): 78.96 Impact Factor (2015): 6.391

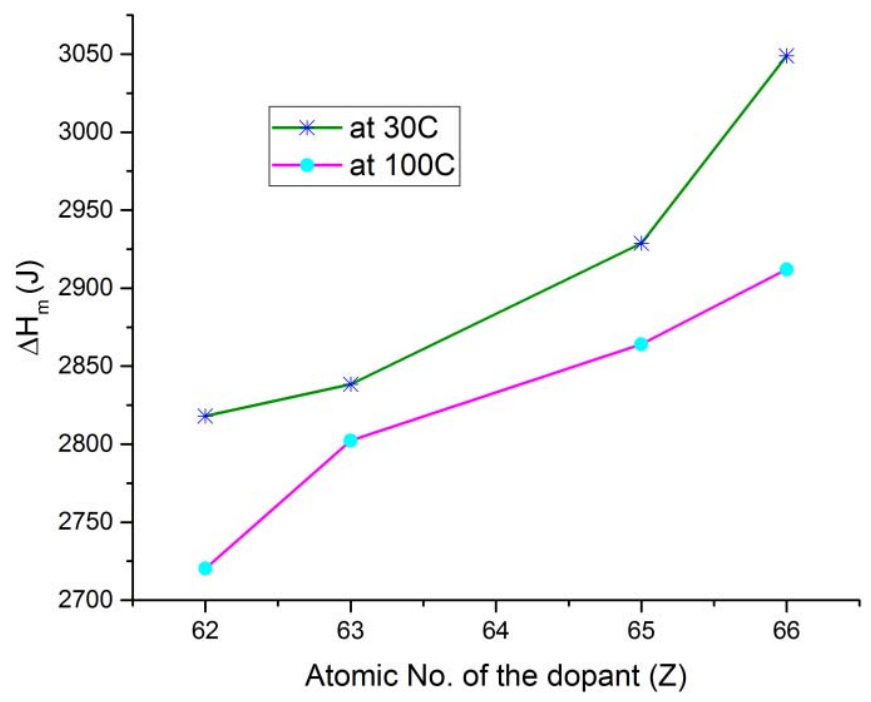

Figure 5: Variation of latent heat of melting $\left(\Delta \mathrm{H}_{\mathrm{m}}\right)$ of MZB glass with atomic no. of rare-earth ion

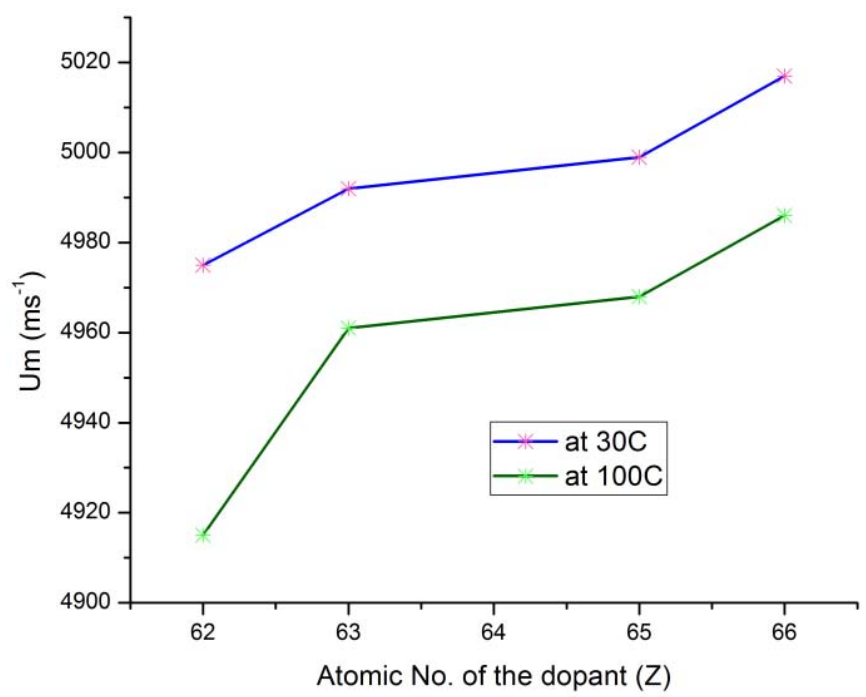

Figure 6: Variation of Mean Velocity $\left(\mathrm{U}_{\mathrm{m}}\right)$ of MZB glass with atomic no. of rare-earth ion

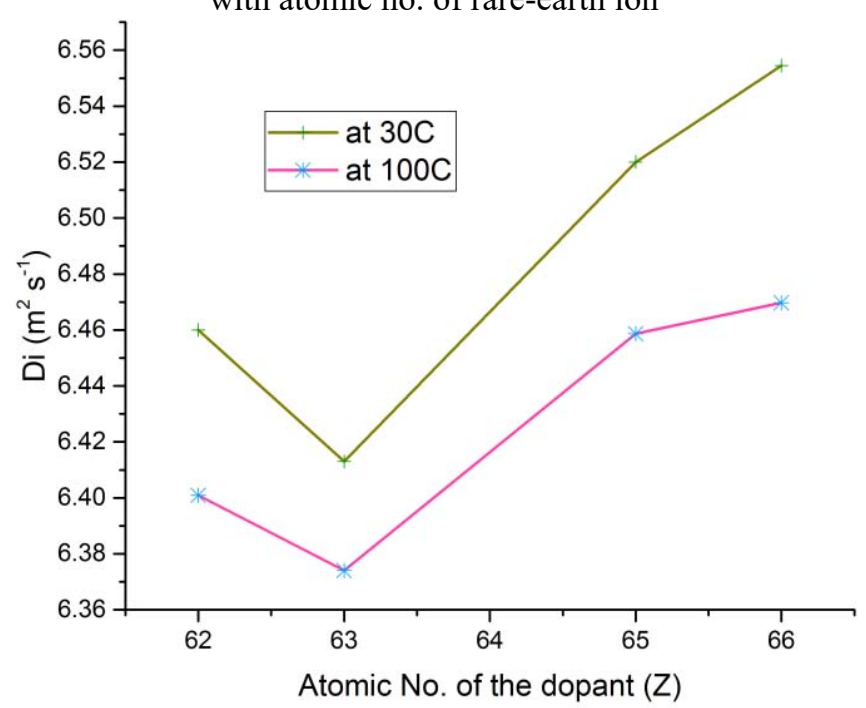

Figure 7: Variation of internal friction with atomic no. of rare-earth ion of MZB glass

In general, in a less disordered glass framework the energy introduced by the vibrator is distributed more rapidly among the vibrational degrees of freedom of the glass framework.
The time required for the establishment of equilibrium distribution of energy goes on decreasing in comparison with the period of oscillation of the vibrator and hence a decrease in the mechanical loss factor or coefficient of internal friction leading to an increase in the elastic coefficients of these glasses (with decrease in the ionic radius of rare earth dopants) is observed in the present measurements. Increase in the temperature of the measurement causes an enhancement of the depolymerisation of the glass network leading to an increase in the mechanical loss factor; such an increase in the loss factor may be responsible for decrease in these values [4].

The observed increasing and decreasing value of $\theta_{\mathrm{D}}$ and $\mathrm{T}_{\mathrm{s}}$ are related to the changes occur in compactness, thermal stability and cross-link density of the glass network. Srivastava and Srinivasan [20] have stated that the thermal expansion coefficient of materials depends on the strength of bonds. the acoustic impedance increases in the glass system attributed to the presence of bridging oxygens and increase in rigidity of the glass structure. Similar trend is observed by Raghavaiah and Veeraiah [19].

\section{Conclusions}

Our study on various elastic/acoustic properties of MZB: $\mathrm{Ln}^{3+}$ glasses indicates that MZB glasses seemed to be more suitable (as far as mechanical strength is concerned) hosts for the rare-earth ions. Further, the increase in micro hardness (H) and Poisson's ratio ( $\square$ ) shows that the atoms experience higher transverse contracting strain and hence become more tightly packed. Further the increase of acoustic impedance and thermal expansion coefficient are due to increase in rigidity of the structure of the glass. The increasing trend of Debye temperature values confirms the occurrence of strong ring formation in MZB glasses. To further elaborate the understanding of MZB glasses compositional dependence of acoustic properties are needed and are proposed to carry. It is also important to see how these MZB glasses are useful for other rare earth ions than $\mathrm{Sm}^{3+}, \mathrm{Eu}^{3+}, \mathrm{Tb}^{3+}$ and $\mathrm{Dy}^{3+}$.

\section{References}

[1] J J. Philip, "Temperature dependence of elastic and dielectric properties of (Bi2O3)1-X, (CUO)X oxide glasse," Journal of Materials Science, vol. 35, p. 229, 2000

[2] F. A. Khalifa, H. A. El Batal, and V. Rajendran, "Behaviour of ultrasonic waves on chromium doped $\mathrm{XPbO}(100 \mathrm{X}) \mathrm{B} 2 \mathrm{O} 3$ glasses," Egyptian Journal of Chemistry, vol. 41, p. 329, 1998

[3] S. P. Yawale, S. V. Pakade, and C. S. Adganokar, "New type of behavior in ultrasonic velocity and adiabatic compressibility of $\mathrm{Bi}_{2} \mathrm{O}_{3}-\mathrm{B}_{2} \mathrm{O}_{3}$ glass," Acoustica, vol. 81, pp. 184, 1995.

[4] M. S. Gaafar, Y. B. Saddeek, and L. Abd El-Latif, "Ultrasonic studies on alkali borate tungstate glasses," J. of Phy. and Chem.of Solids, vol. 70, no. 1, pp. 173-179, 2009

[5] M.S. Gaafar, F.H. El-Batal, M. El-Gazery and S.A. Mansour "effect of doping by different transition metals

\section{Volume 6 Issue 1, January 2017




\section{International Journal of Science and Research (IJSR) \\ ISSN (Online): 2319-7064}

Index Copernicus Value (2015): 78.96 Impact Factor (2015): 6.391

on the acoustical properties of alkali borate glasses" ACTA PHYSICA POLONICA A vol. 115, no.3, pp. 671-678 Jan. 2009.

[6] M Rami Reddy, S Bangaru Raju and N Veeraiah "Acoustic investigations on $\mathrm{PbO}-\mathrm{Al} 2 \mathrm{O} 3-\mathrm{B} 2 \mathrm{O} 3$ glasses doped with certain rare earth ions" Bull. Mater. Sci., Vol. 24, No. 1, pp. 63-68, Feb. 2001.

[7] P. Vasantharani and N. Sangeetha "Physical and elastic properties of mixed alkali borate glasses using ultrasonic technique" Indian journal of applied research vol. 3. No. 9, pp. 429-431, Sep. 2013.

[8] A. N. Kannappan, S. Thirumaran and R. Palani "elastic and mechanical properties of glass specimen by ultrasonic method" ARPN J. of Eng. and App. Sci. vol. 4, no. 1, pp. 27-31, Feb. 2009.

[9] Griscom, D.L., Borate Glasses: Structure, Properties and Applications. Plenum Press, New York, 1978.

[10]F.H. El-Batal, M.A. Azooz and F.M. Ezz-Eldin, "Thermal expansion and infrared studies of binary Bi2O3-B2O3 and ternary Bi2O3-B2O3-PbO glasses," Phys. Chem. Glasses vol. 43, pp. 260-266, 2002.

[11]G. Senthil Murugan, E. Fargin, V. Rodriguez, F. Adamirtz, M. Couzi, T. Buffeteau and P. Le Coustumer, "Temperature-assisted electrical poling of TeO2-Bi2O3$\mathrm{ZnO}$ glasses for non-linear optical applications," J. NonCryst. Solids vol. 344, pp.158-166, 2004.

[12] G.D. Khattak, N. Tabet and L.E. Wenger, "Structural properties of glasses in the series $(\mathrm{SrO}) \mathrm{x}(\mathrm{V} 2 \mathrm{O} 5) 1-\mathrm{x}$, (SrO)0.5-y(B2O3)y(V2O5)0.5, and (SrO)0.2(B2O3)z(V2O5)0.8-z," Phys. Rev. B vol. 72, pp. 104203-104214, 2005.

[13] S. Murugavel and B. Roling, "Ion transport mechanism in borate glasses: Influence of network structure on nonArrhenius conductivity," Phys. Rev. B vol. 76, pp. 180202-180205, 2007.

[14]Dimitrij Lezal, Jitka Pedlikova, Petr Kostka, Jana Bludska, Marcel Poulain and Jiri Zavadil, "Heavy metal oxide glasses: preparation and physical properties," J. Non-Cryst. Solids vol. 284, pp. 288-295, 2001.

[15] J. Lin, W. Huang, Z. Sun, C. S. Ray and D. E. Day, "Structure and non-linear optical performance of TeO2Nb2O5-ZnO glasses," J. Non-Cryst. Solids vol. 336, pp. 189-194, 2004.

[16] W.H. Dumbaugh and J.C. Lapp, "Heavy-Metal oxide glasses," J. Am. Ceram. Soc. Vol. 75, pp. 2315-2326, 1992.

[17] M. Venkateswarlu and B. H. Rudramadevi "luminescence Analysis of Eu3+ and Tb3+ ions doped Borate Zinc Magnesium Glasses," Int. J. of Sci. and Res.(IJSR) Volume 4 no. 4, pp. 3179-3184, April 2015

[18] M. Venkateswarlu, V. Naresh, R. Ramaraghavulu, B. H. Rudramadevi and S. Buddhudu "luminescence Analysis of Eu3+ and Tb3+ ions doped Borate Zinc Magnesium Glasses,” Int. J. of Eng. Res. and Apps. Volume 4 no. 4, pp. 103-113, April 2014

[19] Raghavariah, B.V. and Veeraiah, N, "The role of AS2O3 on the stability and some physical properties of $\mathrm{PbO}$ Sb2O3 glasses," J.Phys. \& Chem. Sol, 65, pp. 1153 114.

[20] Srivastava, C.M., C. Srinivasan, "Science of Engineering Materials, 2nd edition, new age international (P) Ltd., New Delhi, 1997.

\section{Author Profile}

M. Zahir Ahmed received the M.Sc. degrees in Physics from Shibaura Institute of Technology in 1997 and 1999, respectively. During 1997-1999, he is Associate Professor and incharge of Department of Physics, Osmania College Kurnool, A.P., India. He has 28 years of teaching experience.

S. Haranatha Sarma received the M.Sc. degrees in Physics from Sri Krishnadevaraya University in 1996. He is Assistant Professor of Physics, Osmania College Kurnool, A.P., India. He has 20 years of teaching experience. Published several papers in reputed journals and presented papers in international seminars. 